\title{
Probabilistic Models to Predict the Growth Initiation Time for Pseudomonas spp. in Processed Meats Formulated with $\mathrm{NaCl}$ and $\mathrm{NaNO}_{2}$
}

\author{
Hyunji Jo, Beomyoung Park¹, Mihwa Oh${ }^{1}$, Eunji Gwak, Heeyoung Lee, Soomin Lee, and Yohan Yoon* \\ Department of Food and Nutrition, Sookmyung Women's University, Seoul 140-742, Korea \\ ${ }^{1}$ National Institute of Animal Science, RDA, Suwon 441-706, Korea
}

\begin{abstract}
This study developed probabilistic models to determine the initiation time of growth of Pseudomonas spp. in combinations with $\mathrm{NaNO}_{2}$ and $\mathrm{NaCl}$ concentrations during storage at different temperatures. The combination of $8 \mathrm{NaCl}$ concentrations $(0,0.25,0.5,0.75,1,1.25,1.5$, and $1.75 \%)$ and $9 \mathrm{NaNO}_{2}$ concentrations $(0,15,30,45,60,75,90,105$, and $120 \mathrm{ppm})$ were prepared in a nutrient broth. The medium was placed in the wells of 96-well microtiter plates, followed by inoculation of a five-strain mixture of Pseudomonas in each well. All microtiter plates were incubated at $4,7,10,12$, and $15^{\circ} \mathrm{C}$ for 528 , 504, 504, 360 and $144 \mathrm{~h}$, respectively. Growth (growth initiation; GI) or no growth was then determined by turbidity every $24 \mathrm{~h}$. These growth response data were analyzed by a logistic regression to produce growth/no growth interface of Pseudomonas spp. and to calculate GI time. $\mathrm{NaCl}$ and $\mathrm{NaNO}_{2}$ were significantly effective $(p<0.05)$ on inhibiting Pseudomonas spp. growth when stored at $4-12^{\circ} \mathrm{C}$. The developed model showed that at lower $\mathrm{NaCl}$ concentration, higher $\mathrm{NaNO}_{2}$ level was required to inhibit Pseudomonas growth at $4-12^{\circ} \mathrm{C}$. However, at $15^{\circ} \mathrm{C}$, there was no significant effect of $\mathrm{NaCl}_{\text {and }} \mathrm{NaNO}_{2}$. The model overestimated GI times by $58.2 \pm 17.5$ to $79.4 \pm 11 \%$. These results indicate that the probabilistic models developed in this study should be useful in calculating the GI times of Pseudomonas spp. in combination with $\mathrm{NaCl}$ and $\mathrm{NaNO}_{2}$ concentrations, considering the over-prediction percentage.
\end{abstract}

Keywords: Pseudomonas aeruginosa, Pseudomonas fluorescens, $\mathrm{NaCl}, \mathrm{NaNO}_{2}$, processed meats

\section{Introduction}

Pseudomonas spp. are psychrotrophic bacteria, and they are the main cause for milk spoilage (Reddy et al., 1969), chicken (Pittard et al., 1982), fish (Miller et al., 1973), and meat especially at chill temperatures (Nychas et al., 2008). In food, they produce special fluorescent green, yellow or bluish compounds (Brown et al., 1958). Moreover, they generate off-odors in the meats by producing prolyitc and lipolyic enzymes (Champagne et al., 1994; Sorhaug and Stepaniak, 1997). Although Pseudomonas spp. causes physicochemical changes, microbiological criteria for the bacteria are not established because they are not pathogenic bacteria.

In processed meat products, $\mathrm{NaNO}_{2}$ plays an important role in developing of cured meat color and flavor, retarding lipid autoxidation, and preventing Clostridium botuli-

\footnotetext{
*Corresponding author: Yohan Yoon, Department of Food and Nutrition, Sookmyung Women's University, Seoul 140-742, Korea. Tel: +82-2-2077-7585, Fax: +82-2-710-9479, E-mail: yyoon@sookmyung.ac.kr
}

num germination in anaerobic condition (Pegg and Shahidi, 2006). However, $\mathrm{NaNO}_{2}$ has the potential to produce $\mathrm{N}$-nitroso compounds under acidic conditions in stomach (Sugimura, 2000). $N$-nitroso compounds have been found to cause carcinogenic activity in many animal models (Cassens, 1995). Hence, consumers have low acceptance level for processed meat products. Even though processed meat products formulated with low concentrations of $\mathrm{NaNO}_{2}$ have been developed to avoid potential side effects, but the concern for microbial safety due to lowered concentrations of $\mathrm{NaNO}_{2}$ has now increased (Sinedlar et al., 2007).

$\mathrm{NaCl}$ has been used to improve water-holding capacity, fat binding properties, flavor and the inhibition of microbial growth in processed meat products (Guàrdia et al., 2006; Rhee and Zipirin, 2001). However, the high level of $\mathrm{NaCl}$ intake is related to hypertension (Tobian et al., 1979), cardiac failure (Frolich, 1999), and stroke (Perry and Beevers, 1992). Thus, consumers are willing to have the low concentration of $\mathrm{NaCl}$ in processed meat products, but this low $\mathrm{NaCl}$ concentration may not inhibit bacterial growth. Therefore, the minimum concentrations of 
$\mathrm{NaNO}_{2}$ and $\mathrm{NaCl}$ need to be determined to inhibit bacterial growth and also to meet consumers' requirement. Thus, the interactive responses for these two ingredients should be considered in order to determine the minimum concentrations. The probabilistic model should be appropriate to achieve this goal. Probabilistic model using logistic regression can estimate the probabilities of bacterial growth and interface between growth and no growth of bacteria under various conditions (López-Malo et al., 2000; Tienungoon et al., 2000). This mathematical technique can be applied to estimate the GI time of foodrelated bacteria.

Most studies on the relationship between Pseudomonas spp. and $\mathrm{NaNO}_{2}$ have focused on the antimicrobial effect of $\mathrm{NaNO}_{2}$ on Pseudomonas spp. (Henry and Bessieres, 1984; Nicke et al., 2013), but the combination effect of $\mathrm{NaNO}_{2}$ and $\mathrm{NaCl}$ on Pseudomonas spp. in processed meats has not been fully studied yet.

Therefore, the objective of this study was to develop probabilistic models to determine the GI time of Pseudomonas spp. in combinations with $\mathrm{NaNO}_{2}$ and $\mathrm{NaCl}$ concentrations.

\section{Materials and Methods}

\section{Inoculum preparation}

The isolated colonies of Pseudomonas aeruginosa strains (NCCP10338, NCCP10250, and NCCP11229) and Pseudomonas fluorescens strains (KACC10326 and KACC 10323) in Cetrimide agar (Becton Dickinson and Company, USA) were cultured in a nutrient broth (NB; Becton Dickinson and Company) at $35^{\circ} \mathrm{C}$ for $24 \mathrm{~h}$. One hundred microliter fractions of the cultures were transferred into $10 \mathrm{~mL} \mathrm{NB}$ for subculture at $35^{\circ} \mathrm{C}$ for $24 \mathrm{~h}$. After incubation, five strains were mixed and centrifuged at $1,912 \mathrm{~g}$ and $4^{\circ} \mathrm{C}$ for $15 \mathrm{~min}$, and cell pellet was washed twice with phosphate-buffered saline (PBS; pH 7.4; $0.2 \mathrm{~g}$ of $\mathrm{KH}_{2} \mathrm{PO}_{4}, 1.5 \mathrm{~g}$ of $\mathrm{Na}_{2} \mathrm{HPO}_{4} \cdot 7 \mathrm{H}_{2} \mathrm{O}, 8.0$ of $\mathrm{NaCl}$, and $0.2 \mathrm{~g}$ of $\mathrm{KCl}$ in $1 \mathrm{~L}$ of distilled water). The cell suspension was diluted with PBS to $5 \mathrm{Log} \mathrm{CFU} / \mathrm{mL}$.

\section{Growth/no growth response}

The combination of 8 levels $(0,0.25,0.5,0.75,1,1.25$, 1.5 , and $1.75 \%$ ) of $\mathrm{NaCl}$ (Samchun pure chemical Co. Ltd., Korea) and 9 levels $(0,15,30,45,60,75,90,105$, and $120 \mathrm{ppm}$ ) of $\mathrm{NaNO}_{2}$ (Duksan pure chemicals Co. Ltd., Korea) were prepared in NB. Two hundred and twenty five microliters of the medium were placed in wells of 96-well microtiter plates, and $25 \mu \mathrm{L}$ of inoculum was inoculated into each well. All microtiter plate wells were then incubated at $4,7,10,12$, and $15^{\circ} \mathrm{C}$ for 528 , 504, 504, 360, and $144 \mathrm{~h}$, respectively. Growth (growth initiation; GI) or no growth was then determined by turbidity every $24 \mathrm{~h}$. The combinations that became turbid, were considered growth, while the unturbid combination was considered no growth. The growth response was regarded as ' 1 ' and no growth response was assigned as '0' (Koutsoumanis et al., 2004).

\section{Probabilistic model development}

The growth response data were analyzed with the SAS version 9.2 logistic regression analysis (SAS Institute Inc., USA) to estimate the growth probabilities of Pseudomonas spp. Significant parameters were selected through a stepwise selection method $(p<0.05)$.

Logit $(\mathrm{P})=a_{0}+a_{1} \cdot \mathrm{NaCl}+a_{2} \cdot \mathrm{NaNO}_{2}+a_{3} \cdot$ Time $+a_{4} \cdot \mathrm{Na}$ $\mathrm{Cl}^{2}+a_{5} \cdot \mathrm{NaNO}_{2}{ }^{2}+a_{6} \cdot$ Time $^{2}+a_{7} \cdot \mathrm{NaCl} \cdot \mathrm{NaNO}_{2}+a_{8} \cdot \mathrm{NaCl} \cdot$ Time $+a_{9} \cdot \mathrm{NaNO}_{2} \cdot$ Time

Where Logit $(\mathrm{P})$ is an abbreviation of $\ln [\mathrm{P} /(1-\mathrm{P})], \mathrm{P}$ is the probability of growth within the range of 0 to $1, a_{i}$ is the estimates, $\mathrm{NaCl}$ is $\mathrm{NaCl}$ concentrations, $\mathrm{NaNO}_{2}$ is $\mathrm{NaNO}_{2}$ concentrations, and Time is storage time.

\section{Evaluation of developed model}

Observed data for Pseudomonas spp. growth were obtained from commercial frankfurters and bacon. The frankfurters and bacon were cut into $7 \mathrm{~g}$ and placed into plastic bags (Food Saver ${ }^{\circledR}$, Rollpack, Korea). The $0.1 \mathrm{~mL}$ portions of the inoculum were inoculated on one side of the sample surface. The inoculated samples were massaged 15 times in order to spread the bacteria and then sealed using a packager (Food Guard ${ }^{\circledR}$; Rollpack, Korea). The samples were then aerobically stored at $4,7,12$, and $15^{\circ} \mathrm{C}$ for $336,312,192$, and $120 \mathrm{~h}$, respectively. To quantify bacterial populations, the samples were analyzed at appropriate intervals. The $30 \mathrm{~mL}$ of $0.1 \%$ buffered peptone water (BPW; Becton Dickinson and Company) was added into the sample bag and homogenized using a pummeler (BagMixer ${ }^{\circledR}$, Interscience, France) for $60 \mathrm{~s}$. The homogenates were serially diluted with $0.1 \% \mathrm{BPW}$, and $0.1 \mathrm{~mL}$ of the diluents was surface-plated on Cetrimide agar. The plates were incubated at $35^{\circ} \mathrm{C}$ for $24 \mathrm{~h}$, and the typical colonies were manually counted to determine GI time. A growth greater than 1-log considered growth (Koutsomanis et al., 2004; Lee et al., 2013). The observed GI times were then compared to the predicted GI times of 
Pseudomonas spp. estimated under the developed model.

\section{Results and Discussion}

The estimates of coefficients selected from the logistic regression analysis, using an automatic variable selection option with a stepwise selection method, are shown in Table 1. The estimates were then used to produce interfaces between growth and no growth of Pseudomonas spp. at $0.1,0.5$, and 0.9 of probabilities with the combination for $\mathrm{NaNO}_{2}$ and $\mathrm{NaCl}$ level for each storage temperature (Figs. 1-2). This result can also be used to determine
(A) $\mathrm{NaCl} 0 \%$

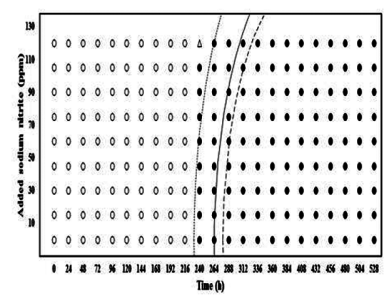

(C) $\mathrm{NaCl} 0.5 \%$

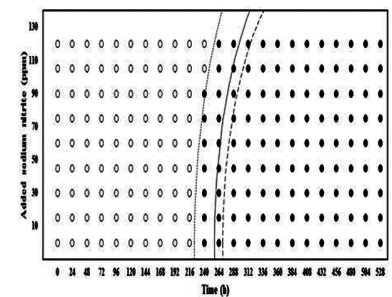

(E) $\mathrm{NaCl} 1 \%$

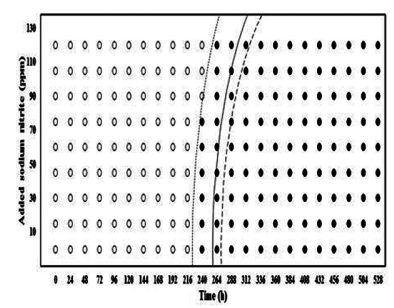

(G) $\mathrm{NaCl} 1.5 \%$

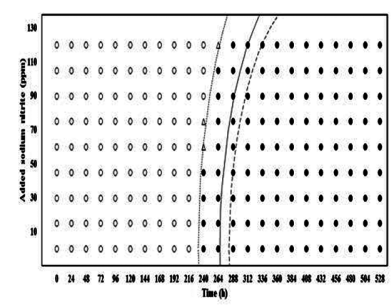

(B) $\mathrm{NaCl} 0.25 \%$

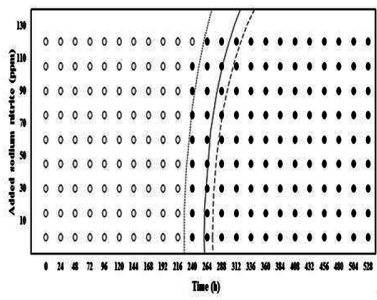

(D) $\mathrm{NaCl} 0.75 \%$

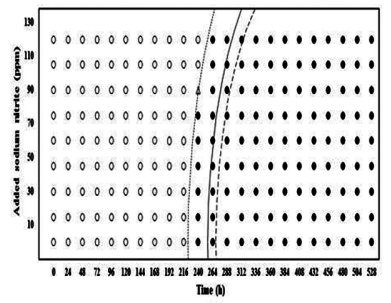

(F) $\mathrm{NaCl} 1.25 \%$

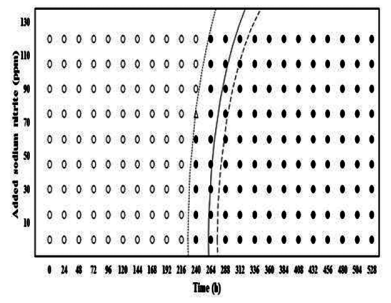

(H) $\mathrm{NaCl} 1.75 \%$

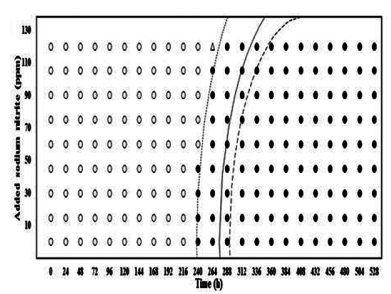

Fig. 1. Growth/no-growth interfaces of Pseudomonas spp. at $4^{\circ} \mathrm{C}$ with respect to $\mathrm{NaNO}_{2}$ concentration and storage time as a function of $\mathrm{NaCl}$ levels at growth probabilities of 0.1 (left line), 0.5 (middle line), and 0.9 (right line); no growth: $\bigcirc$, growth: $\bullet, 50 \%$ growth: $\triangle$. the GI time of Pseudomonas spp. $\mathrm{NaCl}, \mathrm{NaNO}_{2}$, and storage time were generally significant $(p<0.05)$ factors for inhibiting Pseudomonas spp. growth during storage at 4$12^{\circ} \mathrm{C}$ (Table 1). However, $\mathrm{NaNO}_{2}$ and $\mathrm{NaCl}$ did not have any significant effects on the growth of the bacteria at $15^{\circ} \mathrm{C}$. Moreover, a square function for $\mathrm{NaCl}$ and $\mathrm{NaNO}_{2}$ was not observed at 12 and $15^{\circ} \mathrm{C}$ (Table 1).

For 4 and $7^{\circ} \mathrm{C}$, the antimicrobial effect of $\mathrm{NaNO}_{2}$ on Pseudomonas spp. growth slightly increased to $1 \% \mathrm{NaCl}$, but the antimicrobial effect dramatically increased to $1.25 \% \mathrm{NaCl}$ (Figs. 1 and 2). This result indicates that the obvious antimicrobial effect of $\mathrm{NaNO}_{2}$ to inhibit Pseudo-
(A) $\mathrm{NaCl} 0 \%$

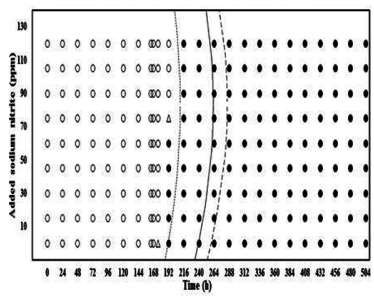

(C) $\mathrm{NaCl} 0.5 \%$

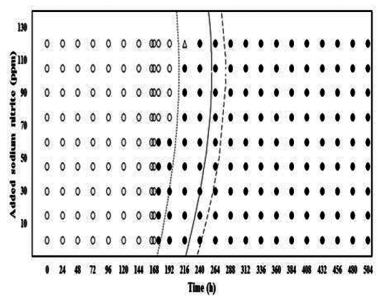

(E) $\mathrm{NaCl} 1 \%$

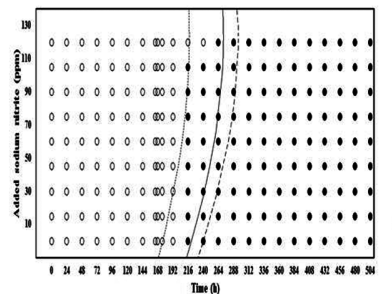

(G) $\mathrm{NaCl} 1.5 \%$

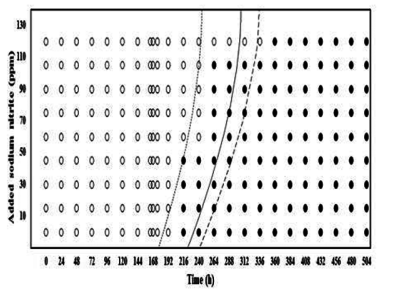

(B) $\mathrm{NaCl} 0.25 \%$

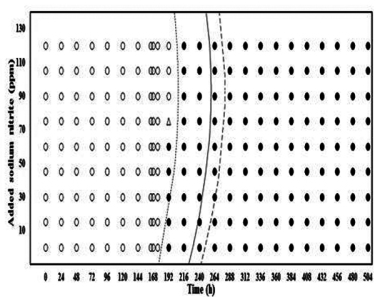

(D) $\mathrm{NaCl} 0.75 \%$

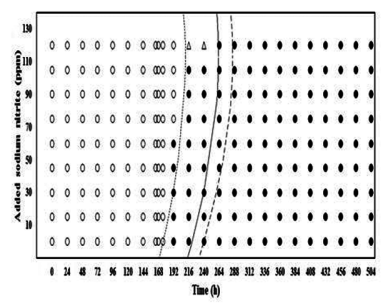

(F) $\mathrm{NaCl} 1.25 \%$

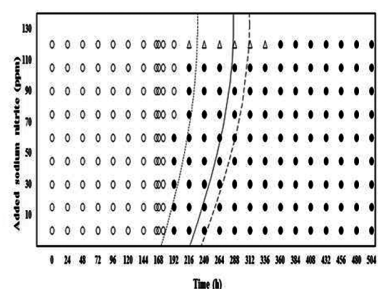

(H) $\mathrm{NaCl} 1.75 \%$

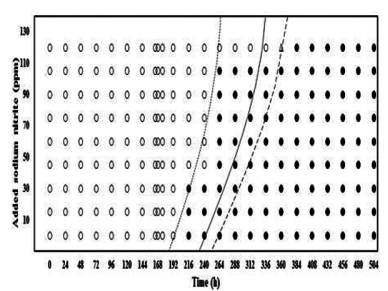

Fig. 2. Growth/no-growth interfaces of Pseudomonas spp. at $7^{\circ} \mathrm{C}$ with respect to $\mathrm{NaNO}_{2}$ concentration and storage time as a function of $\mathrm{NaCl}$ levels at growth probabilities of 0.1 (left line), 0.5 (middle line), and 0.9 (right line); no growth: $\bigcirc$, growth: $\bullet, 50 \%$ growth: $\triangle$. 
monas spp. growth can be found in high $\mathrm{NaCl}$ concentration $(>1.25 \% \mathrm{NaCl})$. In addition, the combination effect of $\mathrm{NaCl}$ and $\mathrm{NaNO}_{2}$ on the inhibition of Pseudomonas spp. growth was also observed at 10,12 , and $15^{\circ} \mathrm{C}$ (data not shown). According to these results, it is suggested that $\mathrm{NaCl}$ concentration of ready-to-eat meat products should be at a certain level to have the obvious antimicrobial effect of $\mathrm{NaNO}_{2}$ on Pseudomonas spp. growth. This is proven by the result from Fig. 3, showing that the difference of growth probability among $\mathrm{NaNO}_{2}$ concentrations became more obvious as $\mathrm{NaCl}$ concentration increased. Similarly, a study by Pelroy et al. (1994) also showed that the concentration-dependent antimicrobial effect of $\mathrm{NaNO}_{2}$ on L. monocytogenes in cold-processed salmon in high $\mathrm{NaCl}$ concentrations when stored at 5 and $10^{\circ} \mathrm{C}$.
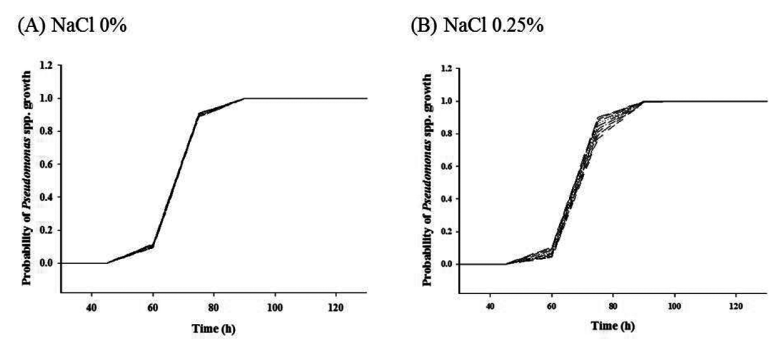

(C) $\mathrm{NaCl} 0.5 \%$

(D) $\mathrm{NaCl} 0.75 \%$
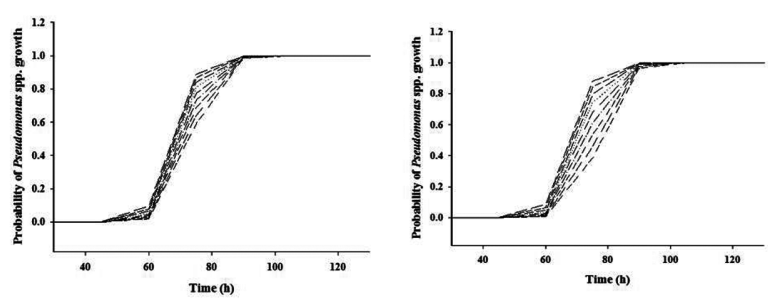

(E) $\mathrm{NaCl} 1 \%$

(F) $\mathrm{NaCl} 1.25 \%$

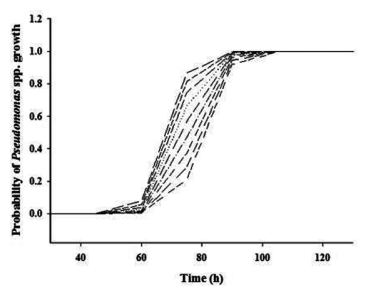

(G) $\mathrm{NaCl} 1.5 \%$

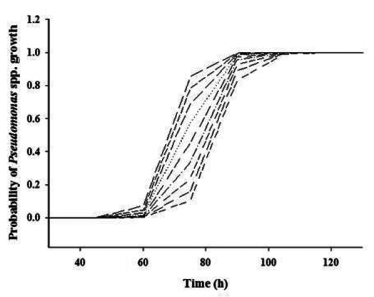

(H) $\mathrm{NaCl} 1.75 \%$
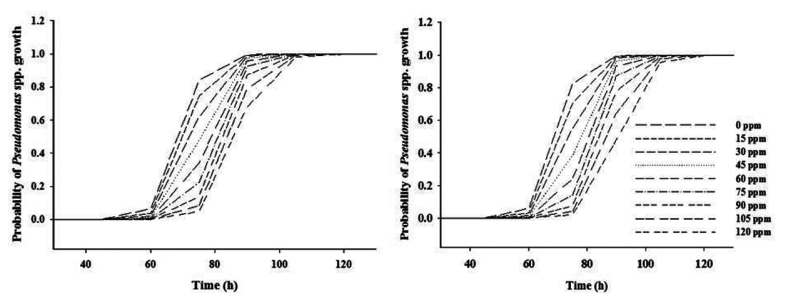

Fig. 3. Probabilities of Pseudomonas spp. at different levels of $\mathrm{NaCl}$ and $\mathrm{NaNO}_{2}$ when stored at $15^{\circ} \mathrm{C}$.
Shahamat et al. (1980) and Buchanan et al. (1989) examined the antimicrobial effects of $\mathrm{NaNO}_{2}$ on $L$. monocytogenes and suggested that the antilisterial effect is improved with $\mathrm{NaCl}$ and other factor such as $\mathrm{pH}$, and temperature. Hence, Allaker et al. (2001) suggested that even though the specific inhibitory modes of nitrite are not well clarified, its antimicrobial effectiveness depends on several factors including salt concentration, $\mathrm{pH}$, reductants, iron content, and others.

The concordance index was used in order to measure the goodness of fit in the developed probabilistic model. The concordance index indicated the degree of agreement between the observations and calculated probabilities. In this study, the concordance index was $94.5-98.1 \%$, while the discordance was $1.9-5.3 \%$, depending on the storage temperature (data not shown).

To evaluate the performance of the developed probabilistic models in this study, the model performance was assessed with the observed data. The predicted GI times calculated by the estimates of the parameters listed in Table 1 at the probability level of 0.5 were then compared to the predicted GI times (Table 2). A growth more than 1-log scale was considered 'growth'. The developments of the growth/no growth model were compared with the observed growth data. The predicted GI times were generally overestimated when compared to the observed values by $58.2 \pm 17.5 \%$ to $79.4 \pm 11 \%$. This result indicates that Pseudomonas spp. initiated to grow earlier in frankfurter and bacon than in broth media by 58.2-79.4\%. Over-prediction percentages were $79.4 \pm 11 \%\left(4^{\circ} \mathrm{C}\right), 66.4 \pm 14.6 \%$ $\left(7^{\circ} \mathrm{C}\right), 58.2 \pm 17.5 \%\left(12^{\circ} \mathrm{C}\right)$, and $68.2 \pm 2.1 \%\left(15^{\circ} \mathrm{C}\right)$ (Table $2)$. In our study, the broth media became turbid, when Pseudomonas spp. grew up to approximately 5-6 Log $\mathrm{CFU} / \mathrm{mL}$, and at the point, Pseudomonas spp. growth was determined. However, data from ready-to-eat meats were considered as "growth" if a growth greater than 1-log was observed. Because of this reason, there was a difference between the predicted data and the observed data. Therefore, decreased GI time by 58.2 to $79.4 \%$ compared to the predicted GI time from developed probabilistic model should be applied for real processed meat products such as frankfurters and bacon.

In conclusion, the probabilistic models developed in this study can be used to calculate the GI times of Pseudomonas spp. in frankfurters and bacon as a function of $\mathrm{NaCl}$ and $\mathrm{NaNO}_{2}$ concentrations, considering the over-prediction percentage, and thus, the probabilistic models can be useful in controlling bacterial spoilage in the processed meats by Pseudomonas spp. 


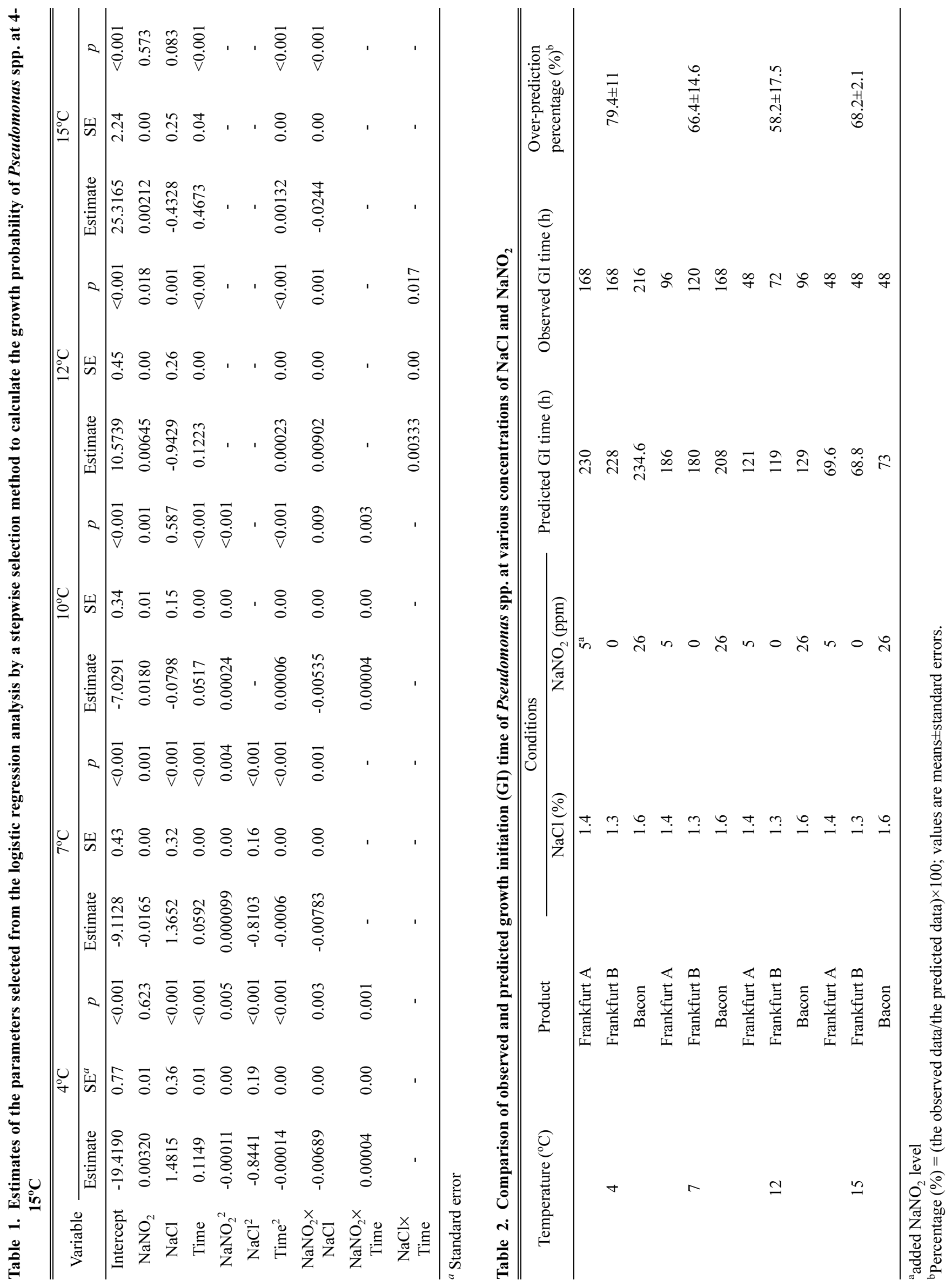




\section{Acknowledgements}

This work was carried out with the support of "Cooperative Research Program for Agriculture Science \& Technology Development (Project No. PJ009237)" Rural Development Administration, Republic of Korea.

\section{References}

1. Allaker, R. P., Silva Mendez, L. S., Hardie, J. M., and Benjamin, N. (2001) Antimicrobial effect of acidified nitrite on periodontal bacteria. Oral Microbiol. Immunol. 16, 253-256.

2. Brown, A. D. and Weidemann, J. F. (1958) The taxonomy of the psychrophilic meat-spoilage bacteria: a reassessment. $J$. Appl. Bacteriol. 21, 11-17.

3. Buchanan, R. L., Stahl, H. G., and Whiting, R. C. (1989) Effects and interactions of temperature, $\mathrm{pH}$, atmosphere, sodium chloride, and sodium nitrite on the growth of Listeria monocytogenes. J. Food Prot. 52, 844-851.

4. Cassens, R. G. (1995) Use of sodium nitrite in cured meats today. Food Technol. 49, 72-80.

5. Champagne, C. P., Laing, R. R., Roy, D., and Mafu, A. A. (1994) Psychrotrophs in dairy products: Their effects and their control. Crit. Rev. Food Sci. Nutr. 34, 1-30.

6. Frolich, E. D. (1999) Risk mechanisms in hypertensive heart disease. Hypertension. 34, 782-789.

7. Guàrdia, M. D., Guerrero, L., Gelabert, J., Gou, P., and Arnau, J. (2006) Consumer attitude towards sodium reduction in meat products and acceptability of fermented sausages with reduced sodium content. Meat Sci. 73, 484-490.

8. Henry, Y. and Bessieres, P. (1984) Denitrification and nitrite reduction: Pseudomonas aeruginosa nitrite-reductase. Biochimie 66, 259-289.

9. Koutsoumanis, K. P., Kendall, P. A., and Sofos, J. N. (2004) Modeling the boundaries of growth of Salmonella Typhimurium in broth as a function of temperature, water activity, and pH. J. Food Prot. 67, 53-59.

10. Lee, S., Lee, H., Lee, J. Y., Skandamis, P., Park, B. Y., Oh, M. H., and Yoon, Y. (2013) Mathematical models to predict kinetic behavior and growth probabilities of Listeria monocytogenes on pork skin at constant and dynamic temperatures. J. Food Prot. 76, 1868-1872.

11. López-Malo, A., Guerrero, S., and Alzamora, S. M. (2000) Probabilistic modeling of Saccharomyces cerevisiae inhibition under the effects of water activity, $\mathrm{pH}$, and potassium sorbate concentration. J. Food Prot. 63, 91-95.

12. Miller, A., III, Scanlan, R. A., Lee, J. S., and Libbey, L. M. (1973) Volatile compounds produced in sterile fish muscle (Sebastes melanops) by Pseudomonas putrefaciens, Pseudomonas fluorescens, and an Achromobacter species. Appl. Microbiol. 26, 18-21.
13. Nicke, T., Schitzer, T., Munch, K., Adamczack, J., Hqufschildt, K., Buchmeier, S., Kucklick, M., Felgentrager, U., Jansch, L., Riedel, K., and Layer, G. (2013) Maturation of the cytochrome $c d l$ nitrite reductase NirS from Pseudomonas aeruginosa requires transient interactions between the three proteins NirS, NirN and NirF. Biosci. Rep. 33, 529-539.

14. Nychas, G. J. E., Skandamis, P. N., Tassou, C. C., and Koutsoumanis, K. P. (2008) Meat spoilage during distribution. Meat Sci. 78, 77-89.

15. Pegg, R. B. and Shahidi, F. (2006) Processing of nitrite-free cured meats. In L. Nollet, M. L., and Todra, F. (Eds.). Advanced Technologies for Meat Processing. Boca Raton, FL: Taylor \& Francis Group, CRC Press, LLC.

16. Pelroy, G., Peterson, M., Paranjpye, R., Almond, J., and Eklund, M. (1994) Inhibition of Listeria monocytogenes in coldprocess (smoked) salmon by sodium nitrite and packaging method. J. Food Prot. 57, 114-119.

17. Perry, I. J. and Beevers, D. G. (1992) Salt intake and stroke: a possible direct effect. J. Hum. Hypertens. 6, 23-25.

18. Pittard, B. T., Freeman, L. R., Later, D. W., and Lee, M. L. (1982) Identification of volatile organic compounds produced by fluorescent pseudomonads on chicken breast muscle. Appl. Environ. Microb. 43, 1504-1506.

19. Reddy, M. C., Bills, D. D., and Lindsay, R. C. (1969) Ester production by Pseudomonas fragi. II. Factors influencing ester levels in milk cultures. Appl. Microbiol. 17, 779-782.

20. Rhee, K. S. and Zipirin, Y. A. (2001) Pro-oxidative effects of $\mathrm{NaCl}$ in microbial growth-controlled and uncontrolled beef and chicken. Meat Sci. 57, 105-112.

21. Shahamat, M., Seaman, A., and Woodbine, M. (1980) Influence of sodium chloride, $\mathrm{pH}$ and temperature on the inhibitory activity of sodium nitrite on Listeria monocytogenes. Soc. Appl. Bacteriol. 15, 227-237.

22. Sindelar, J. J., Cordray, J. C., Olson, D. G., Sebranek, J. G., and Love, J. A. (2007) Investigating quality attributes and consumer acceptance of uncured, no-nitrate/ nitrite-added commercial hams, bacons, and frankfurters. J. Food Sci. 72, 551-559.

23. Sorhaug, T. and Stepaniak, L. (1997) Psychrotrophs and their enzymes in milk and dairy products: quality aspects. Trends Food Sci. Technol. 8, 35-40.

24. Sugimura, T. (2000) Nutrition and dietary carcinogens. Carcinogenesis. 21, 387-395.

25. Tienungoon, S., Ratkowsky, D. A., McMeekin, T. A., and Ross, T. (2000) Growth limits of Listeria monocytogenes as a function of temperature, $\mathrm{pH}, \mathrm{NaCl}$, and lactic acid. Appl. Environ. Microb. 66, 4979-4987.

26. Tobian, L., Lange, J., Iwai, J., Hiller, K., Johnson, M. A., and Goossens, P. (1979) Prevention with thiazide of NaCl-induced hypertension in Dahl "S" rats. Evidence for a Na-retaining humoral agent in "S" rats. J. Am. Heart Assoc. 1, 316-323.

(Received 2014.4.14/Revised 2014.9.15/Accepted 2014.9.16) 